\title{
Variation in Genotype and Aggressiveness of Ralstonia solanacearum Race 1 Isolated from Tomato in Taiwan
}

\author{
Thierry X. Jaunet and Jaw-Fen Wang
}

Asian Vegetable Research and Development Center, P.O. Box 42, Shanhua, Tainan, Taiwan 741, R.O.C. Accepted for publication 23 December 1998.

\begin{abstract}
Jaunet, T. X., and Wang, J.-F. 1999. Variation in genotype and aggressiveness diversity of Ralstonia solanacearum race 1 isolated from tomato in Taiwan. Phytopathology 89:320-327.

A population of Ralstonia solanacearum race 1 from tomato (Lycopersicon esculentum) was analyzed for genetic polymorphism and aggressiveness on tomato. The 46 strains were collected from main tomato-growing areas in Taiwan. Genetic analysis was achieved by two polymerase chain reaction (PCR)-based methods: REP-, ERIC-, and BOX-PCR (collectively as rep-PCR) and random amplified polymorphic DNA (RAPD) techniques. RAPD (with three 10-mers) and rep-PCR revealed 35 and 30 haplotypes, respectively, that were grouped in 14 clusters and 3 clusters, respectively.

Distribution of strains into genetic clusters did not appear related to biovar or geographic origin in considering RAPD, rep-PCR, or composite data. Although strains were more dissimilar based on RAPD data than on rep-PCR data, the two techniques gave complementary results for strain clustering. A set of 40 strains representing the main haplotypes was inoculated on six tomato cultivars differing in their bacterial wilt resistance. Six groups differing in general level of aggressiveness and cultivar specificity were detected. Although populations were highly diverse in both genotype and aggressiveness, no association was found between the two characteristics. Although the sample sizes in this study were not adequate to draw definite conclusions about population structure, these results will be valuable for future population genetic studies on $R$. solanacearum.
\end{abstract}

Bacterial wilt, caused by race 1 strains of Ralstonia solanacearum, is a major disease of tomato in the tropics and subtropics. Disease incidences of 15 to $55 \%$ have been reported in fresh market tomato, causing over US\$12 million losses annually in Taiwan (10). The pathogen is soilborne and has an extremely wide host range (13). Thus, planting resistant cultivars is the most effective means of disease control. However, one of the main problems encountered in resistance deployment has been the location specificity of resistance. A worldwide field evaluation in 11 countries of a set of 35 resistance sources to bacterial wilt in tomato has clearly demonstrated existence of location-specific resistance in most sources (30). Location specificity can be related to dependence of resistance on environmental conditions, especially temperature (24). However, strain-specific quantitative resistance loci have been identified in the two mapping populations from the resistant tomato lines L 285 (6) and Hawaii 7996 (31). Resistance breakdown could, therefore, be related to pathogen diversity.

$R$. solanacearum is a highly variable species encompassing five biovars and five races (13). Levels of genetic variability differ greatly among the three main races (5). Strains of race 3 have a restricted host range, mostly affecting potato, and appear to be more genetically diverse in the potato's region of origin than in other parts of the world (27). Comparison of race 3 populations isolated from potato pointed to a high level of genetic diversity in South America, while Kenyan populations consisted of only one major clone. In contrast, race 1 strains are highly diverse in several tropical areas, as demonstrated by solanaceous crops in the West Indies (8), groundnut in Malaysia (26), and various hosts in Australia (9).

Neutral markers detected by various molecular techniques have been used in determination of genetic variability and of factors structuring pathogen populations $(18,21)$. The genetic structure of

Corresponding author: J.-F. Wang; E-mail address: jfw@ netra.avrdc.org.tw

Publication no. P-1999-0212-01R

(C) 1999 The American Phytopathological Society plant pathogen populations is shaped by different selection pressures, depending on the agroecological environment (21). Among them, host genotype, natural habitat, and cultural practices have been proven to be important (11). For example, host diversity has been assumed to be an important factor explaining the genetic differentiation at the geographic level of populations of Xanthomonas axonopodis pv. manihotis in Colombia (25) and X. oryzae pv. oryzae in the Philippines (1). R. solanacearum is a soilborne pathogen. A high level of genetic diversity has been reported in different soilborne bacterial species (28). Genetic differentiation of soilborne bacterial populations can take place at the microgeographic level depending on soil and host rhizosphere properties, as demonstrated for Burkholderia cepacia populations $(7,20)$. However, little is known about factors shaping the populations of $R$. solanacearum.

Variation of aggressiveness in $R$. solanacearum race 1 strains has been demonstrated in Taiwan and the French West Indies (16, 24). However, past studies on variation of race 1 strains did not include many strains isolated from tomato. Understanding variation in pathogen populations is the key for successful breeding and deployment of plant resistance $(18,21)$. The most important pathogen phenotype to consider for resistance deployment is the interaction with specific host cultivars. However, races of $R$. solanacearum are defined by host range rather than by cultivar specificity. Previous research revealed that the response of different tomato cultivars to $R$. solanacearum was more quantitative than qualitative $(16,24)$. Therefore, the term "aggressiveness" is more appropriate than "virulence" to describe interaction between $R$. solanacearum and tomato. In this study, we attempted to use several tomato cultivars, differing in their resistance levels, to examine variability of aggressiveness this pathogen.

Studies on population genetics of the pathogen may provide a better understanding of the location-specific nature of resistance to bacterial wilt in tomato. Therefore, the purpose of this study was to determine the existing variation among strains present in tomato-production fields by examining a small but representative population. Genetic variation was determined using two polymerase 
chain reaction (PCR)-based techniques and aggressive variation was determined by inoculating defined tomato cultivars.

\section{MATERIALS AND METHODS}

Bacterial strains. A total of 46 strains of $R$. solanacearum was used in this study (Table 1). They were selected from the Asian Vegetable Research and Development Center (AVRDC) culture collection and represented strains from the main tomato-growing areas of Taiwan. Most strains (42) were collected during 1994 to 1997 and three strains were collected during 1990 to 1991. Strain 4 (Pss 4) isolated in 1987 and used for routine resistance screening at the AVRDC was included for comparison. The identification of strains was confirmed by PCR using $R$. solanacearum-specific primer pair AU759f (GTCGCCGTCAACTCACTTTCC) and AU760r (GTCGCCGTCAGCAATGCGGAATCG) (23). For all 46 strains, a 281-bp band specific for $R$. solanacearum was amplified. Before further analysis, pathogenicity of the strains was evaluated by inoculating a susceptible tomato line, L 390. The tips of three leaflets were clipped with a pair of scissors that were dipped in a bacterial suspension $\left(\mathrm{OD}_{600}=0.4\right)$. Inoculated plants were kept in a greenhouse at temperatures ranging from 25 to $35^{\circ} \mathrm{C}$. All strains tested produced wilting symptoms no later than 14 days after inoculation and were considered pathogenic. Strains were assigned to biovars according to Hayward (12).

Random amplified polymorphic DNA (RAPD) analysis. Genomic DNA from each strain was extracted following the method of Chen and Kuo (4). Three 10-mer primers, OPAD1, OPAG6, and OPAG14 (Operon Technologies Inc., Alameda, CA), were used for RAPD amplification. These three primers reveal polymorphism among $R$. solanacearum strains (M. Fegan; personal communication). The $25-\mu \mathrm{l}$ reaction mixture consisted of $10 \mathrm{mM}$ Tris- $\mathrm{HCl}(\mathrm{pH} 8.8) ; 50 \mathrm{mM} \mathrm{KCl} ; 0.1 \%$ Triton X100; $1.5 \mathrm{mM}$ $\mathrm{MgCl}_{2} ; 125 \mu \mathrm{M}$ each of dATP, dCTP, dTTP, and dGTP; 15 pmol of primer; 1 unit of DNA polymerase Prozyme II (Protech, Taipei, Taiwan); and $50 \mathrm{ng}$ of template DNA. Amplifications were performed in an automated thermal cycler (Perkin-Elmer 480; PerkinElmer, Foster City, CA). The initial denaturation at $94^{\circ} \mathrm{C}$ for $5 \mathrm{~min}$ was followed by 40 cycles of $94^{\circ} \mathrm{C}$ for $1 \mathrm{~min}, 37^{\circ} \mathrm{C}$ for $1 \mathrm{~min}$, and $72^{\circ} \mathrm{C}$ for $2 \mathrm{~min}$. The final extension was at $72^{\circ} \mathrm{C}$ for $5 \mathrm{~min}$. A $7.5-\mu \mathrm{l}$ portion of the RAPD product was resolved on a $1.5 \%$ agarose gel in $0.5 \times$ Tris-borate-EDTA buffer at $6.7 \mathrm{~V} / \mathrm{cm}$; the gel was stained with ethidium bromide and photographed on an UV transilluminator. For 10 randomly selected strains, PCR amplifications using the three primers were repeated three times to test the reproducibility of this assay. The banding patterns of these 10 strains included most common bands. However, when a strain yielded unique bands, the PCR amplification was repeated for confirmation.

REP-, ERIC-, and BOX-PCR (rep-PCR) analysis. The repPCR method was adapted from Smith et al. (27). The three primer sets REP (REP1R-I, REP2-I), ERIC (ERIC1R, ERIC2), and BOX (BOXA1R) are those described by Louws et al. (19) and were

TABLE 1. Geographic origin of Ralstonia solanacearum strains isolated from tomato in Taiwan and distribution of biovars

\begin{tabular}{|c|c|c|c|c|}
\hline Region & County & $\begin{array}{c}\text { Year } \\
\text { of collection }\end{array}$ & Biovar & $\begin{array}{l}\text { Number } \\
\text { of strains }\end{array}$ \\
\hline North & Taipei & 1995 & 4 & 2 \\
\hline \multirow[t]{2}{*}{ Northeast } & Ilan & 1995,1997 & 3 & 14 \\
\hline & & & 4 & 4 \\
\hline \multirow[t]{2}{*}{ Northwest } & Hsinchu & 1996 & 3 & 4 \\
\hline & & & 4 & 3 \\
\hline Central & Nantou & 1994,1995 & 3 & 6 \\
\hline West & Yunlin & 1994 & 3 & 1 \\
\hline \multirow{2}{*}{ Southwest } & Tainan, Chiayi & 1987, 1994, 1995, 1997 & 3 & 3 \\
\hline & & & 4 & 6 \\
\hline \multirow[t]{2}{*}{ Southeast } & Taitung & 1990, 1991 & 3 & 1 \\
\hline & & & 4 & 2 \\
\hline
\end{tabular}

synthesized by Gibco BRL (Life Technologies, Green Island, NY). The 25- $\mu \mathrm{l}$ reaction mixture consisted of $10 \mathrm{mM}$ Tris- $\mathrm{HCl}(\mathrm{pH} \mathrm{8.8)}$; $50 \mathrm{mM} \mathrm{KCl} ; 0.1 \%$ Triton X100; $1.5 \mathrm{mM} \mathrm{MgCl}_{2} ; 200 \mu \mathrm{M}$ each of dATP, dCTP, dTTP, and dGTP; 30 pmol of primer; 0.5 unit of DNA polymerase Prozyme II; and $100 \mathrm{ng}$ of template DNA. Amplifications were performed in an automated thermal cycler (Hybaid TouchDown; Hybaid, Ltd., Teddington, United Kingdom). The initial denaturation at $95^{\circ} \mathrm{C}$ for $7 \mathrm{~min}$ was followed by 30 cycles of $94^{\circ} \mathrm{C}$ for $1 \mathrm{~min} ; 44,52$, or $53^{\circ} \mathrm{C}$ for $1 \mathrm{~min}$ for REP, ERIC, and $\mathrm{BOX}$, respectively; and $65^{\circ} \mathrm{C}$ for $8 \mathrm{~min}$. The final extension was at $65^{\circ} \mathrm{C}$ for $15 \mathrm{~min}$. A 6 - $\mu$ l portion of the rep-PCR product was resolved on a $2 \%$ agarose gel in $1 \times$ Tris-acetate-EDTA buffer at $5 \mathrm{~V} / \mathrm{cm}$; the gel was stained with ethidium bromide and photographed on an UV transilluminator. The reproducibility of rep-PCR amplification was verified as described above for RAPD analysis.

Analysis of fingerprinting data. Each unique banding pattern generated by RAPD or rep-PCR alone, or the combination of both methods, was considered to represent a haplotype. The presence or absence of a band at each position along a lane was converted to binary data ( 1 for presence and 0 for absence). The Nei and $\mathrm{Li}$ (22) coefficient of similarity (NL), which is suitable for RAPD data (17), was used for a pairwise comparison of strains and transformed into a dissimilarity coefficient (1-NL) by NTSYS-pc (version 1.80; Exeter Biological Software, Setauket, NY). A tree was generated by the unweighted pair group method with arithmetic mean (UPGMA), and the robustness of the tree branches was tested with a bootstrap analysis with 2,000 iterations by the program Winboot (32). Clusters were determined using an average linkage method, and the most reliable number of clusters was determined based on a consensus among three clustering criteria (cubic clustering criterion, pseudo- $F$, and pseudo- $t^{2}$ ) by SAS/IML (version 6.10, SAS/IML software; SAS Institute, Inc., Cary, NC).

Analysis of aggressiveness. Forty strains selected according to their composite RAPD and rep-PCR profiles were evaluated for aggressiveness on six tomato cultivars differing in bacterial wilt resistance (Table 2). Five of the tomato cultivars (Lycopersicon esculentum) were selected on the basis of their mean percent survival in 12 field trials conducted in 11 countries worldwide (30). 'L 180-1' (L. pimpinellifolium) is a wild tomato accession that is resistant to bacterial wilt (J.-F. Wang, unpublished data). Aggressiveness was evaluated in a greenhouse under natural light with temperatures ranging from 24 to $27^{\circ} \mathrm{C}$. Plants were grown in individual 2 -inch pots and inoculated at the four-true-leaf stage. Inoculation was performed by drenching $20 \mathrm{ml}$ of bacterial suspension $\left(\mathrm{OD}_{600}=0.3\right)$ over the soil surface (31). Plants inoculated with the same strain were placed in one flat, and spacing between flats was at least $15 \mathrm{~cm}$ to avoid contamination. Inoculation of ' $\mathrm{L} 390$ ', 'L 180-1', and 'Hawaii 7996' was done twice with 12 plants arranged in a completely randomized design. Inoculation of ' $\mathrm{L} 180-1$ ', 'Rodade', 'CRA 66', and 'CLN 1463-160-40-60' ('CLN 1463') was performed twice with six plants in a randomized complete block design. The number of wilting plants was recorded every 2 days for 3 weeks. The final frequency of wilting for each strain on the six cultivars was analyzed with principal component analysis by the SAS-PRINCOMP procedure. Aggressive clusters were determined

TABLE 2. Origin of tomato cultivars used in this study and their resistance to Ralstonia solanacearum

\begin{tabular}{lllc}
\hline Cultivar & \multicolumn{1}{c}{ Resistance source } & \multicolumn{1}{c}{ Origin } & $\begin{array}{c}\text { Resistance } \\
\text { level }^{\mathrm{a}}\end{array}$ \\
\hline Hawaii 7996 & PI 127805 A & Hawaii, United States & 97.0 \\
CRA 66 & CRA 66 & French West Indies & 87.5 \\
CLN 1463 & UPCA 1169, Saturn, CRA 84-26-3 & Taiwan & 69.5 \\
Rodade & BW2 & South Africa & 56.5 \\
L 180-1 & LA 1466 & Peru & $\ldots$ \\
L 390 & Susceptible check & Taiwan & 13.3 \\
\hline
\end{tabular}

a Mean percent survival from a worldwide trial conducted in 12 fields (30); 'L 180-1' was not included in this trial. 
by using an average linkage method and the three clustering criteria (cubic clustering criterion, pseudo- $F$, and pseudo- $t^{2}$ ) by SAS.

\section{RESULTS}

Aggressiveness. Variation in aggressiveness among the 40 strains from the Taiwan population was observed by inoculating six tomato cultivars. Mean final percent wilting over strains was $44.8 \%$ over the six tested cultivars, ranging from $8.6 \%$ for 'Hawaii 7996 ' to $81.5 \%$ for ' $L 390$ '. Principal component and cluster analyses of final wilting revealed six aggressiveness groups among the 40 strains (Fig. 1). The first two principal components accounted for $61 \%$ of the standardized variance, with 44 and $17 \%$ for the first and second components, respectively. The loading of all cultivars was approximately equal for the first component. Thus, this component gave a good measure of overall aggressiveness. The second component had high positive loading on the two replications of the resistant cultivars Hawaii 7996 and CLN 1463 and high negative loading on the two replications of the cultivars L 390 and CRA 66. Thus, the first two components differentiated strains according to both their general aggressiveness and their specific cultivar interaction. The two strains 190 and 191 belonging to aggressiveness group 1 were highly aggressive on all six cultivars, with an average final wilting of $94 \pm 5 \%$. Aggressiveness groups 2, 4, 5, and 6, encompassing 7, 14, 7, and 5 strains, respectively, were similar in their interaction with tomato cultivars, but showed a decrease in general aggressiveness with an average final wilting of $67 \pm 7,49 \pm 5$, $32 \pm 6$, and $9 \pm 5 \%$, respectively. Aggressiveness group 3, encompassing five strains from the northeastern region of Taiwan, showed a unique pattern of interaction with the tested cultivars. Although the average final wilting was $37 \pm 8 \%$, strains in this group were less aggressive on 'L 390' and 'CRA 66' and more aggressive on
'CLN 1463' compared with strains in groups 4 and 5. Final percent wilting on ' $\mathrm{L}$ 390', the susceptible cultivar, and 'CLN 1463' were similar (about $60 \%$ final wilting), while final wilting on 'CRA 66' was similar to that on the resistant cultivar Hawaii 7996 (about $15 \%$ final wilting).

Genetic polymorphism revealed by RAPD and rep-PCR. Both RAPD and rep-PCR generated many distinct fingerprints for the 46 strains isolated from tomato in Taiwan. The three RAPD primers gave a total of 53 band positions ranging from 150 to 2,500 bp, with 12, 21, and 20 band positions for OPAD1, OPAG6, and OPAG14, respectively. Thirty-four haplotypes were defined by RAPD. The three rep-PCR primers gave a total of 28 band positions $(14,3$, and 11 band positions for REP, ERIC, and BOX primers, respectively), ranging from 200 to $4,000 \mathrm{bp}$ and defining 30 haplotypes. The average number of band positions per strain was 10 and 15 with rep-PCR and RAPD primers, respectively. The combination of the 81 band positions from both RAPD and rep-PCR data defined 35 haplotypes. Average dissimilarity between the 46 strains was greater with RAPD (0.44) than with repPCR (0.31). The lower dissimilarity of rep-PCR data resulted in a more compact UPGMA dendrogram than the RAPD tree (Fig. 2). However, the rep-PCR UPGMA tree was less robust than the RAPD tree. The percentage of branches having bootstrap values greater than $75 \%$ was 7 and $28 \%$ for rep-PCR and RAPD data, respectively. The dendrogram constructed from composite data had main branches ascribed to rep-PCR and the secondary ones to RAPD (Figs. 2 and 3). Combining data improved robustness of grouping, as the percentage of branches having bootstrap values greater than $75 \%$ increased to $39 \%$. Results of cluster analysis determined the most reliable number of clusters to be 3 for repPCR data, 14 for RAPD data, and 11 for composite data, based on the three clustering criteria (cubic clustering criterion, pseudo- $F$,

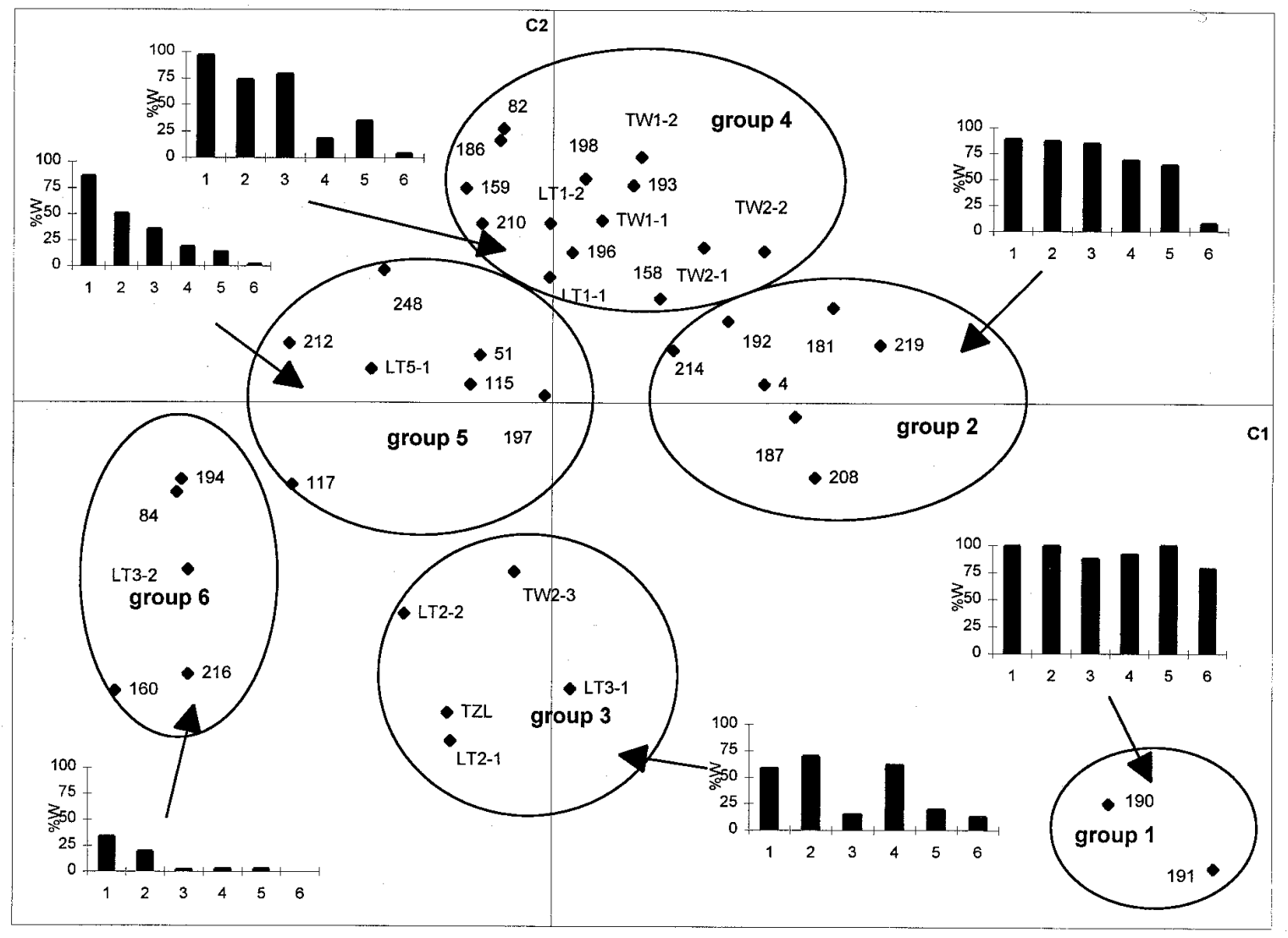

Fig. 1. Results of the principal component and cluster analysis on final percent wilting after inoculation of six tomato cultivars with 40 strains of Ralstonia solanacearum isolated from tomato in Taiwan. Points represent each strain plotted in a plane defined by the first two components $(\mathrm{C} 1 * \mathrm{C} 2)$. Each aggressive group is characterized by a histogram of final percent wilting (\%W) on six cultivars: $1=$ ' $\mathrm{L}$ 390', 2 = 'Rodade', $3=$ 'CRA 66', $4=$ 'CLN 1463', $5=$ 'L 180-1', and $6=$ 'Hawaii 7996'. Histograms were constructed from average percent wilting from all strains within groups. 


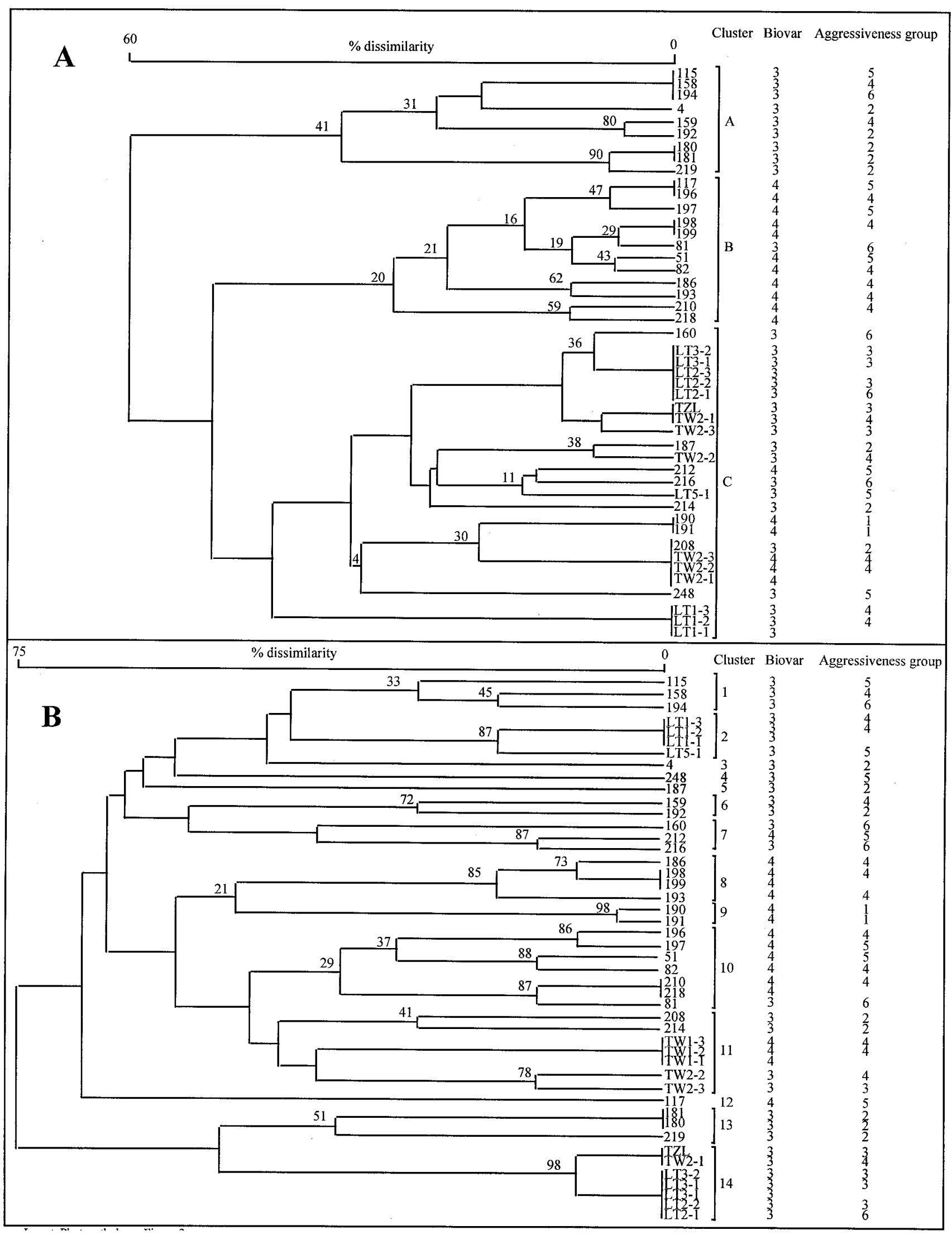

Fig. 2. Dendrograms derived by the unweighted pair group method with arithmetic mean showing dissimilarity between A, rep-polymerase chain reaction (PCR) haplotypes and $\mathbf{B}$, random amplified polymorphic DNA (RAPD) haplotypes of Ralstonia solanacearum strains isolated from tomato in Taiwan. Clusters (based on a consensus among the clustering criteria: cubic clustering criterion, pseudo- $F$, and pseudo- $t^{2}$ ), biovar, aggressive group, and bootstrap values (for branches, representing the percentage of times the group occurred out of 2,000 iterations) are indicated. Branches without bootstrap values indicate that the cluster is not in the bootstrap consensus tree. 
and pseudo- $t^{2}$ ). Comparison of RAPD and rep-PCR clustering showed that each RAPD cluster contained only strains belonging to the same rep-PCR cluster. Although some strains from each rep-PCR cluster were found in different locations in the RAPD dendrogram (Fig. 2), dissimilarity calculated from RAPD data was lower within than between different rep-PCR clusters (Table 3 ). The above results showed that rep-PCR and RAPD data provided close and complementary results.
Pairwise dissimilarity and distribution of strains into clusters using rep-PCR, RAPD, or composite data did not appear related to aggressiveness, biovar, and geographic origin of strains (Table 4). Strains from the same aggressiveness group were distributed randomly among genetic clusters, except for aggressiveness groups 1 and 3 (Figs. 2 and 3). The five strains of the latter group were present in one rep-PCR cluster, two RAPD clusters, and two composite clusters (Figs. 2 and 3). This group was also the only one

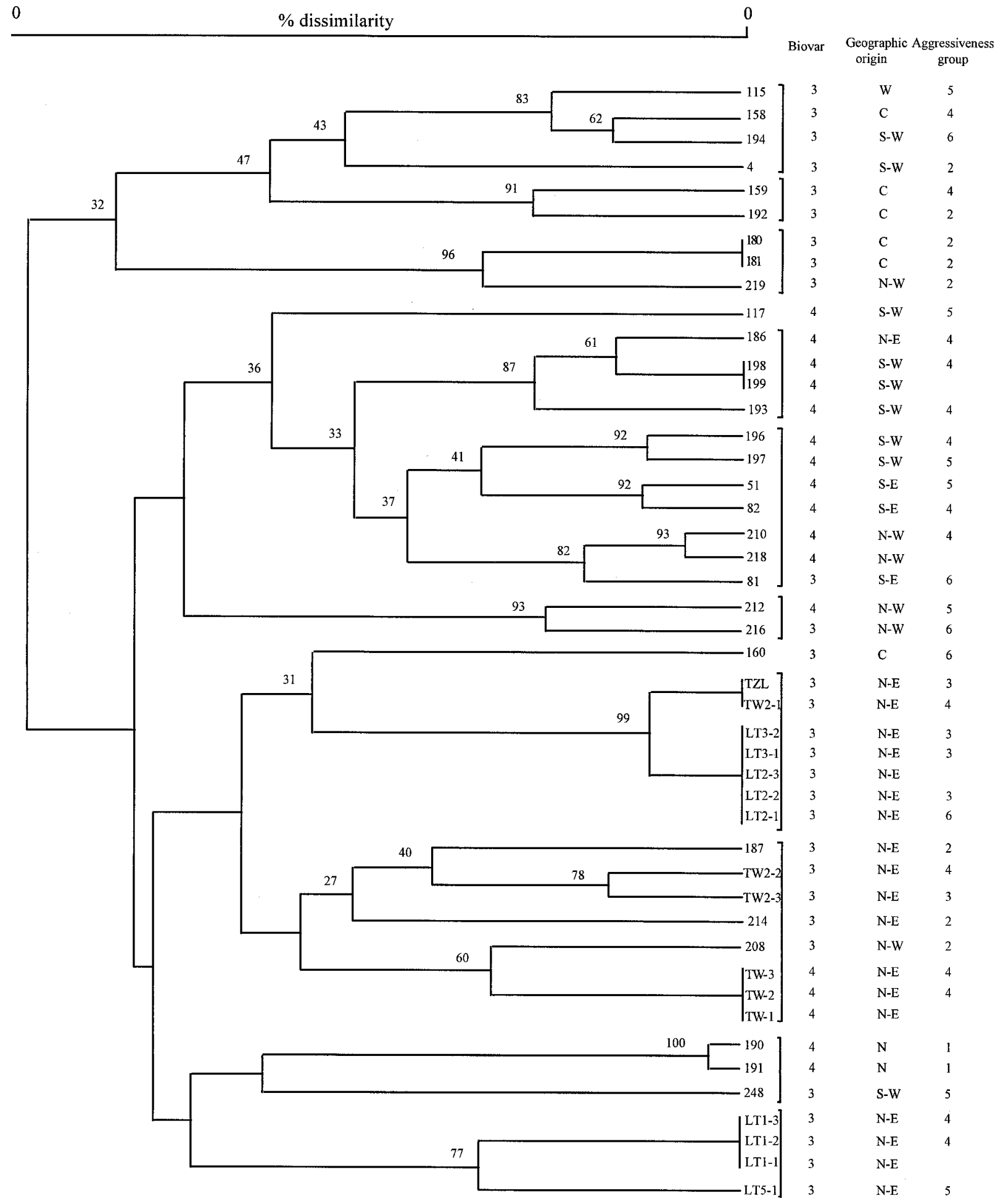

Fig. 3. Dendrograms derived by the unweighted pair group method with arithmetic mean showing dissimilarity between composite rep-polymerase chain reaction (PCR)/random amplified polymorphic DNA (RAPD) haplotypes of Ralstonia solanacearum strains isolated from tomato in Taiwan. Clusters (based on a consensus among the clustering criteria: cubic clustering criterion, pseudo- $F$, and pseudo- $\left.t^{2}\right)$, biovar, geographic origin $(\mathrm{N}=$ north, $\mathrm{N}-\mathrm{E}=$ northeast, $\mathrm{N}-\mathrm{W}=$ northwest, $\mathrm{W}=$ west, $\mathrm{C}=$ central, $\mathrm{S}-\mathrm{W}=$ southwest, and $\mathrm{S}-\mathrm{E}=$ southeast), aggressiveness group, and bootstrap values (for branches, representing the percentage of times the group occurred out of 2,000 iterations) are indicated. Branches without bootstrap values indicate that the cluster is not in the bootstrap consensus tree. 
among the five aggressiveness groups with a sample size larger than two to have a within-group dissimilarity lower than the among-group dissimilarity. In considering biovar, dissimilarity was slightly lower among than between biovars (Table 4). However, biovar 4 strains were more homogeneous than biovar 3 strains, as indicated by the lower dissimilarity over the three data sets. For most of the seven regions, dissimilarity within a region was similar to or slightly lower than dissimilarity between regions (Table 4). Strains from northern and southeastern Taiwan were the most similar, although this result could be related to the small sample size from these two regions.

\section{DISCUSSION}

Using neutral markers generated with RAPD and rep-PCR methods, large genetic variation was observed among strains of $R$. solanacearum from tomato-production fields in Taiwan. The two techniques were efficient in revealing genetic polymorphism in the $R$. solanacearum population. The number of haplotypes defined among the 46 bacterial strains was 30, 34, and 35 haplotypes for rep-PCR, RAPD, and combined rep-PCR/RAPD, respectively. Although dissimilarity among strains was larger with RAPD data than with rep-PCR data, strain clustering by each technique was complementary. Thus, either RAPD or rep-PCR markers are suitable for genetic analysis of $R$. solanacearum. Di Cello et al. (7) used RAPD to reveal genetic diversity of Burkholderia cepacia populations from the rhizosphere of maize. This technique appears to be the simplest and the most flexible method for assessing the population genetic diversity, although the low annealing tempera-

TABLE 3. Distribution of random amplified polymorphic DNA (RAPD) clusters within rep-polymerase chain reaction (PCR) clusters and dissimilarity within and between each rep-PCR cluster using RAPD data from Ralstonia solanacearum strains isolated from tomato in Taiwan

\begin{tabular}{llccc}
\hline & & \multicolumn{3}{c}{ Average dissimilarity } \\
\cline { 3 - 5 } $\begin{array}{l}\text { rep-PCR } \\
\text { cluster }^{\mathrm{a}}\end{array}$ & \multicolumn{1}{c}{ RAPD cluster $^{\mathrm{a}}$} & $\begin{array}{l}\text { rep-PCR } \\
\text { cluster A }\end{array}$ & $\begin{array}{l}\text { rep-PCR } \\
\text { cluster B }\end{array}$ & $\begin{array}{l}\text { rep-PCR } \\
\text { cluster C }\end{array}$ \\
\hline $\mathrm{A}$ & $1,3,6,13$ & 0.36 & & \\
$\mathrm{~B}$ & $8,10,12$ & 0.56 & 0.25 & \\
$\mathrm{C}$ & $2,4,5,7,9,11,14$ & 0.50 & 0.48 & 0.36 \\
\hline
\end{tabular}

a Shown in Figure 2.

${ }^{b}$ Average Nei and Li coefficient of dissimilarity calculated from RAPD data. ture and short primer size used for RAPD may affect amplification reproducibility (3). Thus, this method could be inappropriate in studies intended to compare results from different laboratories.

Different molecular techniques have been used to generate neutral markers to study genetic diversity and structure of plant-pathogenic bacteria. $R$. solanacearum race 1 from the French West Indies (8) and $R$. solanacearum race 3 from Kenya (27) were analyzed both by pulse field gel electrophoresis of large fragments produced by rare cutting restriction endonucleases and by rep-PCR. These methods did not show significant differences in the level of diversity and clustering in either study. Similarly, results of restriction fragment length polymorphism (RFLP) and rep-PCR were correlated when analyzing the $X$. oryzae pv. oryzae population from a single field (29). Unlike the $R$. solanacearum strain grouping, composite data did not improve the robustness of $X$. oryzae pv. oryzae strain clustering, which was high with either method. This difference could be explained by a lower level of polymorphism in the $X$. oryzae pv. oryzae population than in the $R$. solanacearum population.

The high level of genetic polymorphism found among the 46 strains of the Taiwanese $R$. solanacearum population from tomato is similar to that in previous studies on race 1 of $R$. solanacearum, which have shown high genetic variability within populations isolated from solanaceous crops in the French West Indies (8) and from groundnut in Malaysia (26). Both biovars 3 and 4 are present in the Taiwanese population from tomato. Although biovar 4 is more genetically homogeneous than biovar 3, no difference was found in cluster distribution between the two biovars. This result confirms the close genetic relationship between biovars 3 and 4 that was demonstrated by Cook and Sequeira (5) using RFLP analysis.

Inoculation of 40 strains, representing the main haplotypes on six tomato cultivars differing in their resistance to bacterial wilt, revealed six aggressiveness groups (Fig. 1) with mean percent wilting ranging from 9 to $94 \%$ for groups 6 and 1, respectively. The existence of aggressiveness group 3, which contained $11 \%$ of the total strains, indicates that cultivar specificity is not rare. Interestingly, strains in this aggressiveness group are all from Ilan County in northeastern Taiwan. From this result, we may hypothesize that the location specificity of resistance observed in the worldwide evaluation (30) could be related to the large variation in aggressiveness. However, strains from northeastern Taiwan represented the largest sample in our study. Thus, cultivar-specific strains might have been found in other regions if our sample sizes had been

TABLE 4. Dissimilarity among Ralstonia solanacearum strains using rep-polymerase chain reaction (PCR), random amplified polymorphic DNA (RAPD), and composite RAPD/rep-PCR data according to biovar, geographic origin, and aggressiveness

\begin{tabular}{|c|c|c|c|c|c|c|c|}
\hline \multirow[b]{2}{*}{ Level } & \multirow[b]{2}{*}{ No. of strains } & \multicolumn{2}{|c|}{ rep-PCR } & \multicolumn{2}{|c|}{ RAPD } & \multicolumn{2}{|c|}{ Composite rep-PCR/RAPD } \\
\hline & & Among $^{\mathrm{a}}$ & Between $^{\mathrm{b}}$ & Among $^{\mathrm{a}}$ & Between $^{\mathrm{b}}$ & Among $^{\mathrm{a}}$ & Between $^{b}$ \\
\hline \multicolumn{8}{|l|}{ Biovar } \\
\hline 3 & 29 & 0.29 & 0.34 & 0.45 & 0.47 & 0.39 & 0.42 \\
\hline \multicolumn{8}{|l|}{ Origin } \\
\hline Central & 6 & 0.30 & 0.38 & 0.46 & 0.49 & 0.38 & 0.45 \\
\hline Southwest & 9 & 0.25 & 0.31 & 0.39 & 0.44 & 0.33 & 0.38 \\
\hline North & 2 & 0 & 0.28 & 0.03 & 0.39 & 0.02 & 0.34 \\
\hline West & 1 & $\ldots$ & 0.32 & $\ldots$ & 0.46 & $\ldots$ & 0.40 \\
\hline \multicolumn{8}{|c|}{ Aggressiveness group ${ }^{c}$} \\
\hline 1 & 2 & 0 & 0.21 & 0.03 & 0.42 & 0.01 & 0.24 \\
\hline 2 & 7 & 0.24 & 0.24 & 0.50 & 0.48 & 0.26 & 0.26 \\
\hline 3 & 5 & 0.04 & 0.20 & 0.14 & 0.46 & 0.06 & 0.25 \\
\hline
\end{tabular}

a Average Nei and Li coefficient of dissimilarity calculated among strains from each sublevel.

${ }^{b}$ Average Nei and Li coefficient of dissimilarity calculated between strains from the sublevel and strains from all the other sublevels.

${ }^{c}$ Aggressiveness groups were determined according to cluster analysis on final percent wilting after inoculation of six tomato cultivars (Fig. 1). Group 1 corresponds to the most aggressive strains and group 6 to the least aggressive. 
larger. Distribution of strains with different levels of aggressiveness needs to be studied further. For example, the geographic distribution of strains similar to 190 and 191 from aggressiveness group 1 would determine the usefulness of cultivar Hawaii 7996, the most stable resistant cultivar so far identified (30). The finding of cultivar-specific interactions caused by strains in group 3 emphasizes the need to evaluate host-pathogen interaction with more tomato cultivars. Suitable differential cultivars can then be selected for evaluating the total variation in aggressiveness. Pss 4 , the strain used in routine screening at AVRDC, belongs to aggressiveness group 2. Although strains in groups 2, 4, 5, and 6 had similar interactions with the tested tomato cultivars, it remains unknown whether selecting against only Pss 4 is sufficient for incorporating resistance to all strains. More thorough studies are necessary to provide the answer.

Although the population is highly diverse with respect to both haplotypes and aggressiveness, clustering of strains based on these two criteria was not correlated. Only aggressiveness groups 1 and 3 encompassed genetically related strains (Table 4). Leung et al. (18) assumed that absence of association between the genotypic and pathotypic groupings reveals that (i) the pathogen population is strongly selected by host genotype; (ii) the mutation rate of the pathogen is variable; or (iii) the pathotype, as defined by interactions with specific host cultivars, is not the main unit of pathogen evolution. Popular tomato cultivars grown in Taiwan have low levels of resistance to bacterial wilt. The importance of host selection in the genetic structure of $R$. solanacearum populations remains to be determined. Moreover, tomato is only one of many hosts of $R$. solanacearum in Taiwan (14). Inoculation of tomato and perilla (Perilla crispa) with strains isolated from nine different hosts showed that tomato was susceptible to all strains, whereas perilla was susceptible only to its respective strains (15). Thus, susceptibility of tomato to strains from different hosts could help maintain high variability of genotype and aggressiveness in the $R$. solanacearum population from tomato in Taiwan. This assumption is supported by the existence of pathotypes in tomato strains demonstrated by Hsu et al. (16). To confirm this hypothesis of hostrange effect on population genetic structure, pathotyping of the population from tomato by inoculating strains on a range of hosts should be undertaken. The large variability observed in this population of $R$. solanacearum can also be related to its soilborne nature. The pathogen has to cope with the variable environment in the soil during its saprophytic survival (13). Thus, soil properties may play an important role in genetic differentiation, as has been demonstrated for other soilborne bacterial species (20). Furthermore, genetic recombination and horizontal gene exchange may play an important role in the genetic differentiation of soilborne bacteria (11). Although $R$. solanacearum is competent for natural genetic transformation (2), the importance of genetic recombination on shaping population structure remains to be determined.

Although the sample sizes used in this study were not adequate to draw definite conclusions about the genetic structure of $R$. solanacearum populations in Taiwan (21), the results reported here provide direction for future population genetics studies. The large variation in genotype and aggressiveness revealed in the Taiwanese population stresses the importance of large sample sizes and sampling at the regional rather than at the country level. The need for large samples is also necessitated by the occurrence of several biovars within $R$. solanacearum, which can be unevenly distributed at the regional level. Furthermore, lack of association between genotypic and pathotypic variation and the presence of cultivar-specific interactions indicate that analysis of populations based only on neutral markers is not sufficient to fully understand the population diversity of $R$. solanacearum.

\section{ACKNOWLEDGMENTS}

We thank the French Ministry of Foreign Affairs for financial support to T. Jaunet, and the National Science Council of Taiwan (NSC 97-2313-
B-125-001) and the Australian Centre for International Agriculture Research (ACIAR PN 9452) for financial support to J.-F. Wang. We thank C.-F. Hsu for technical assistance.

\section{LITERATURE CITED}

1. Ardales, E. Y., Leung, H., Vera Cruz, C. M., Mew, T. M., Leach, J. E., and Nelson, R. J. 1996. Hierarchical analysis of spatial variation of the rice bacterial blight pathogen across diverse agroecosystems in the Philippines. Phytopathology 86:241-252.

2. Bertolla, F., Van Gijsegem, F., Nesme, X., and Simonet, P. 1997. Conditions for natural transformation of Ralstonia solanacearum. Appl. Environ. Microbiol. 63:4965-4968.

3. Brown, J. K. M. 1996. The choice of molecular marker methods for population genetic studies of plant pathogens. New Phytol. 133:183-195.

4. Chen, W. P., and Kuo, T. T. 1993. A simple and rapid method for preparation of gram-negative bacterial genomic DNA. Nucleic Acids Res. 132:6-13.

5. Cook, D., and Sequeira, L. 1994. Strain differentiation of Pseudomonas solanacearum by molecular genetic methods. Pages 77-94 in: Bacterial Wilt: The Disease and Its Causative Agent, Pseudomonas solanacearum. G. L. Hartman and A. C. Hayward, eds. CAB International, Wallingford, United Kingdom.

6. Danesh, D., and Young, N. D. 1994. Partial resistance loci for tomato bacterial wilt show differential race specificity. Tomato Genet. Coop. Rep. 44:12-13.

7. Di Cello, F., Bevivino, A., Chiarini, L., Fani, R., Paffetti, D., Tabacchioni, S., and Dalmastri, C. 1997. Biodiversity of Burkholderia cepacia population isolated from the maize rhizosphere at different plant growth stages. Appl. Environ. Microbiol. 63:4485-4493.

8. Frey, P., Smith, J. J., Albar, L., Prior, P., Saddler, G. S., Trigalet-Demery, D., and Trigalet, A. 1996. Bacteriocin typing of Burkholderia (Pseudomonas) solanacearum race 1 of the French West Indies and correlation with genomic variation of the pathogen. Appl. Environ. Microbiol. 62: 473-479.

9. Gillings, M. R., and Fahy, P. 1994. Genomic fingerprint: Towards a unified view of Pseudomonas solanacearum species complex. Pages 95-113 in: Bacterial Wilt: The Disease and Its Causative Agent, Pseudomonas solanacearum. G. L. Hartman and A. C. Hayward, eds. CAB International, Wallingford, United Kingdom.

10. Hartman, G. L., Hong, W.-F., and Wang, T.-C. 1991. Survey of bacterial wilt on fresh market hybrid tomatoes in Taiwan. Plant Prot. Bull. (R.O.C.) 33:197-203.

11. Haubold, B., and Rainey, P. B. 1997. Towards an understanding of the population genetics of plant-colonizing bacteria. Adv. Bot. Res. 24:335-351.

12. Hayward, A. C. 1964. Characteristics of Pseudomonas solanacearum. J. Appl. Bacteriol. 27:265-277.

13. Hayward, A. C. 1991. Biology and epidemiology of bacterial wilt caused by Pseudomonas solanacearum. Annu. Rev. Phytopathol. 29:67-87.

14. Hsu, S.-T. 1991. Ecology and control of Pseudomonas solanacearum in Taiwan. (In Chinese.) Plant Prot. Bull. (R.O.C.) 33:72-79.

15. Hsu, S.-T., Hong, W.-F., Tzeng, K.-C., and Chen, C.-C. 1993. Bacterial wilt of perilla caused by Pseudomonas solanacearum and its transmission. Plant Dis. 77:674-677.

16. Hsu, S.-T., Tsai, T.-T., and Tzeng, K.-C. 1979. Pathovars of Pseudomonas solanacearum in Taiwan and their interaction in tobacco plants. (In Chinese.) Natl. Sci. Counc. Mon. (R.O.C.) 7:609-620.

17. Lamboy, W. F. 1994. Computing genetic similarity coefficients from RAPD data: Correcting for the effects of PCR artifacts caused by variation in experimental conditions. PCR Methods Appl. 4:38-43.

18. Leung, H., Nelson, R. J., and Leach, J. E. 1993. Population structure of plant pathogenic fungi and bacteria. Adv. Plant Pathol. 10:157-205.

19. Louws, F. J., Fulbright, D. W., Stephens, E. R., and de Bruijn, F. J. 1994. Specific genomic fingerprints of phytopathogenic Xanthomonas and Pseudomonas pathovars and strains generated with repetitive sequences and PCR. Appl. Environ. Microbiol. 60:2286-2295.

20. McArthur, J. V., Kovacic, D. A., and Smith, M. H. 1988. Genetic diversity in natural populations of soil bacterium across a landscape gradient. Proc. Natl. Acad. Sci. U.S.A. 85:9621-9624.

21. Milgroom, M. G., and Fry, W. E. 1997. Contribution of population genetics to plant disease epidemiology and management. Adv. Bot. Res. $24: 1-25$.

22. Nei, M., and Li, W. H. 1979. Mathematical model for studying genetic variation in terms of restriction endonucleases. Proc. Natl. Acad. Sci. U.S.A. 76:5269-5273.

23. Opina, N., Tavner, F., Hollway, G., Wang, J.-F., Li, T.-H., Maghirang, R., Fegan, M., Hayward, A. C., Krishnapillai, V., Hong, W.-F., Holloway, B. W., and Timmis, J. N. 1997. A novel method for development of species and strain-specific DNA probes and PCR primers for identifying Burk- 
holderia solanacearum (formerly Pseudomonas solanacearum). AsiaPacific J. Mol. Biol. Biotechnol. 5:19-30.

24. Prior, P., Steva, H., and Cadet, P. 1990. Aggressiveness of strains of Pseudomonas solanacearum from the French West Indies (Martinique and Guadeloupe) on tomato. Plant Dis. 74:962-965.

25. Restrepo, S., and Verdier, V. 1997. Geographical differentiation of the population of Xanthomonas axonopodis pv. manihotis in Colombia. Appl. Environ. Microbiol. 63:4427-4434.

26. Smith, J. J., Kibata, G. N., Murimi, Z. K., Lum, K. Y., FernandezNorthcote, E., Offord, L. C., and Saddler, G. S. 1998. Biogeographic studies on Ralstonia solanacearum race 1 and 3 by genomic fingerprinting. Pages 50-55 in: Bacterial Wilt Disease. Molecular and Ecological Aspects. P. Prior, C. Allen, and J. Elphinstone, eds. Springer-Verlag, Berlin, Germany.

27. Smith, J. J., Offord, L. C., Holderness, M., and Saddler, G. S. 1995. Genetic diversity of Burkholderia solanacearum (synonym Pseudomonas solanacearum) race 3 in Kenya. Appl. Environ. Microbiol. 61:4263-4268.

28. Torsvik, V., Sorheim, R., and Goksoyr, J. 1996. Total bacterial diversity in soil and sediment communities-A review. J. Industr. Microbiol. 17:170-178.

29. Vera Cruz, C. M., Ardales, E. Y., Skinner, D. Z., Talag, J., Nelson, R. J., Louws, F. J., Leung, H., Mew, T. W., and Leach, J. E. 1996. Measurement of haplotypic variation in Xanthomonas oryzae pv. oryzae within a single field by rep-PCR and RFLP analysis. Phytopathology 86:1352-1359.

30. Wang, J.-F., Hanson, P., and Barnes, J. A. 1998. Worldwide evaluation of an international set of resistance sources to bacterial wilt in tomato. Pages 269-275 in: Bacterial Wilt Disease. Molecular and Ecological Aspects. P. Prior, C. Allen, and J. Elphinstone, eds. Springer-Verlag, Berlin, Germany.

31. Wang, J.-F., Thoquet, P., Olivier, J., and Grimsley, N. 1998. Genetic analysis of quantitative resistance loci (QRL) of tomato variety Hawaii 7996 in Taiwan. Pages 246-249 in: Bacterial Wilt Disease. Molecular and Ecological Aspects. P. Prior, C. Allen, and J. Elphinstone, eds. Springer-Verlag, Berlin, Germany.

32. Yap, I., and Nelson, R. J. 1996. Winboot: A program for performing bootstrap analysis of binary data to determine the confidence limits of UPGMA-based dendrograms. IRRI Discussion Paper Series 14. International Rice Research Institute, Manila, Philippines. 